\title{
Innovation in the UK fresh produce sector: identifying systemic problems and the move towards systemic
} \section{facilitation}

Jonathan Menary ${ }^{1}$, Rosemary Collier ${ }^{1^{*}} \&$ Kate Seers ${ }^{2}$

${ }^{1}$ Warwick Crop Centre, School of Life Sciences, University of Warwick, Wellesbourne Campus, CV359EF

${ }^{2}$ Warwick Research in Nursing, University of Warwick Medical School, University of Warwick, Coventry CV47AL

Keywords: Agricultural Innovation Systems, functional-structural analysis, agricultural innovation, fresh produce sector, horticulture, qualitative research

Highlights:

- Vertical and horizontal fragmentation caused by loss of public extension services

- Power and information asymmetry between retail suppliers and customers

- Producer organisations increasingly important for innovation processes

- Globalisation of agricultural knowledge development and diffusion

*Corresponding author. Address: Warwick Crop Centre, School of Life Sciences, University of Warwick, Wellesbourne Campus, CV359EF | Tel: +44(0)2476575066 


\section{ABSTRACT}

Innovation has been promoted to help meet the various challenges faced by the UK fresh produce sector. However, what barriers hinder the development and spread of new ideas in the sector have not been investigated. This article explores the social and economic constraints to innovation by combining the agricultural innovation systems (AIS) conceptual framework with a functional-structural analysis. Semi-structured interviews were undertaken with 32 key informants, including growers, agronomists, researchers and representatives from major retailers. The findings show that, whilst the UK fresh produce sector is highly innovative, a number of systemic problems slow or prevent the acquisition and utilisation of knowledge. The privatisation of public extension services has led to a degree of horizontal and vertical fragmentation, with increasingly 'closed' groups and lack of nationwide research coordination or guiding visions for the sector. Variation in business size and crop type make coordination or coherent visions challenging to establish, presenting problems for intermediary organisations in matching the supply and demand of agricultural knowledge. At the same time, a stark power asymmetry exists between suppliers and retail customers, whose policies have led to a "defensive" innovation culture and lack of trust - producer organisations represent a response to this asymmetry, as well as increasingly important factor in the (now globalised) development and diffusion of agricultural innovations. Systemic instruments to facilitate better coordination and communication are proposed, such as innovation platforms to bring together otherwise closed groups around common problems and the use of road-mapping to provide a guiding vision for the future of the sector. Retail-led grower groups also provide a means to improve trust between suppliers and customers in the sector and promote new technological trajectories. 


\section{INTRODUCTION}

In recent years a number of Government strategies have sought to bolster UK agricultural innovation, such as the 'Agri-Tech Strategy' and plant and animal health strategies (UK Government 2013a, 2014a, 2014b). These strategies have primarily promoted (basic) scientific research to boost the competitiveness of the agricultural sector, but have also pointed towards a number of institutional factors that are limiting UK agricultural development: funding for applied and translational research has been lacking, with no adequate substitutes for the publically-funded institutes of the past; the diversity of the industry makes it challenging for institutions to develop new connections; there are no clear measures to recruit and retain new talent in the industry (UK Government 2013a).

In the UK, the agricultural innovation support system - the organisations that help entrepreneurs bring new ideas to market - has undergone significant change since the late 1980s, with the consolidation (and liquidation) of many independent agricultural research institutes. In England, only three remain (Hermans, Klerkx, and Roep 2015). The diverse advisory community that has emerged following the privatisation of extension services has complicated the picture for farmers in accessing suitable knowledge (Klerkx and Proctor 2013). In this post-public extension service environment, firms have a strong interest in protecting the commercial value of knowledge (Lamprinopoulou et al. 2012). Knowledge sharing, even between agricultural advisors, has been found to have declined in countries where formerly public extension services have been privatised (Klerkx, de Grip, and Leeuwis 2006); this is sometimes called horizontal fragmentation. Farm businesses must now be increasingly pro-active in 
seeking out knowledge for innovation, even though they may lack the required competencies for doing so (Klerkx and Leeuwis 2008b).

The competitive tendering system that now characterises agricultural research provision also presents problems for research institutes, universities and other knowledge-based organisations in anticipating and capturing client needs (Klerkx and Leeuwis 2008b; Prager et al. 2016). However, vertical fragmentation, which can be described as a lack of coordination of research activity, has been identified as a problem for the English agricultural system in the post-public extension environment (Hermans et al. 2015).

Intermediary organisations, brokers of the innovation process between two or more parties, are receiving increased attention as a solution to these types of problems (Howells 2006; Klerkx and Leeuwis 2009; Smedlund 2006). In the Netherlands, intermediaries have proliferated in the wake of privatisation (Klerkx and Leeuwis 2008a, 2008b; Meulen, Nedeva, and Braun 2005). It has been noted that the UK has followed a rather distinct trajectory (Lamprinopoulou et al. 2012), retaining a statutory levy board (the Agriculture and Horticulture Development Board, AHDB) with substantial responsibility for capturing research needs, commissioning research projects and disseminating results. A number of problems have been characterised for such organisations in mediating the supply and demand of agricultural knowledge (Klerkx and Leeuwis 2008b): invisibility and immeasurability of service value (Klerkx and Leeuwis 2008a); unclear images of these organisations (i.e. what their precise functions are) due to operational overlap with other knowledge-based organisations (Howells 2006); their focus on organisations already capable of leveraging agricultural R\&D is also problematic (Klerkx and Leeuwis 2008b). 
It has been proposed that, rather than focusing exclusively on the communication and implementation of research results in a linear fashion, knowledge-based organisations should re-orientate their efforts around systemic facilitation. Stimulating the formation of networks, for example, could improve innovation in the agricultural system (van den Driessen Mareeuw et al. 2015; see also Klerkx and Leeuwis 2008b). Managing communication problems between groups is also important, particularly where institutional barriers are slowing the process of innovation - this goes beyond transferring science into practice (Klerkx, Schut, et al. 2012). Supporting the development of innovation platforms (IPs), which are forums to convene relevant innovation stakeholders, can likewise encourage network formation and act as a mechanisms for the identification of institutional barriers to change (Hounkonnou et al. 2012; Klerkx et al. 2013). Given the complexity and interdependent nature of agricultural problems today, systems approaches that can provide a holistic understanding of the competing demands on agriculture are required to determine appropriate intervention points to improve the capacity of the agricultural innovation system (AIS) to innovate (Brooks and Loevinsohn 2011).

A number of existing papers have assessed the performance of the AIS in specific regions of the UK (Hermans et al. 2015; Lamprinopoulou et al. 2012), with less attention paid to sector-specific issues. There is reason to believe that some problems may be unique to or more significant for the fresh produce sector, such as access to labour (on which it remains highly dependent) or the withdrawal of certain pesticides in the European Union that are commonly used to control pests in fruit and vegetable crops (Villaverde et al. 2014). 


\subsection{The UK fresh produce sector}

The fresh produce sector includes the production and processing of fruits, vegetables and ornamental plants. It represents roughly £3.6 billion at farm-gate prices in 2017 (UK Government 2018) and employs around 30,000 permanent and 75,000 non-UK seasonal workers (Office for National Statistics 2018; UK Government 2013b). It can be considered a sub-sector of the wider UK agricultural industry. The potato sector is also included in the scope of this study, though it is not generally considered to be fresh produce. Most fruit and vegetables in the UK (over $80 \%$ ) is sold through supermarket retailers (Sodano and Hingley 2009). The sector is also marked by rationalisation into fewer but larger businesses due to supermarket prerogatives for smaller supplier portfolios, which has in turn led to increasing emphasis on "category management", that is, the management by farm businesses or 'marketing desks' of particular foodstuffs (Sodano and Hingley 2009). These large agri-businesses now operate on pan-European and even global scales (Hingley, Lindgreen, and Casswell 2005; Sodano and Hingley 2009).

The structure of the UK retail market has been described as oligopsonic (Camanzi, Malorgio, and Azcárate 2011; Revoredo-Giha et al. 2012) and the fresh produce sector itself as "cutthroat" (Retail Think Tank, KPMG, and Ipsos Retail Performance 2014). In 2013 a groceries code adjudicator was established by the UK government to ensure the fair treatment of suppliers by retail customers. Although large, influential firms seek to control the food supply chain (Mylan et al. 2015) and contractors use their market power to depress prices for suppliers or make other contract conditions less favourable for producers (Young and Hobbs 2002), this asymmetry of power indicates a market failure that some authors have linked to fragmentation in the wake of extension service 
privatisation (Klerkx and Leeuwis 2009; Klerkx and Proctor 2013; Lamprinopoulou et al. 2012; Leeuwis 2000). It also explains the growth of agricultural cooperatives and producer organisations (POs) in Europe, which represent a reaction to monopsonistic or oligopsonic agricultural markets (Camanzi et al. 2011; Pascucci, Gardebroek, and Dries 2012).

POs can vary in terms of purpose, formality and legal form (Bijman and Hanisch 2012) but represent any organisation of fruit and vegetable producers that is established for a specific purpose (Camanzi et al. 2011) - with 33 fruit and vegetable POs registered in the UK. Camanzi et al. (2011) note that POs can facilitate the improvement of on-farm production techniques by providing technical assistance. A weakness of POs is strong network failure, whereby a group remains closed off to new ideas (Hogeland 2015; Weber and Rohracher 2012). It is not entirely clear what role POs play in the innovation system landscape.

It has been noted that the sector faces a number of distinct challenges: new pests and diseases, restrictions on labour, the price of agricultural inputs and foreign competition (National Horticultural Forum 2011). The sector relies on the "off-label" use of pest control products (i.e. not following labelled guidelines) that have been developed for the arable market (Villaverde et al. 2014), presenting a challenge for the control of any new, fresh produce-specific pests and diseases. The sector's high dependence on manual labour means any constraints to labour availability can significantly affect the ability of farm businesses to operate. Domestic producers are also now competing in a global market for certain categories of produce (Legge et al. 2006). As with the wider agricultural industry, innovation has been promoted to overcome these problems (National Horticultural Forum 2011). Innovation in this context is often implicitly 
technological and focussed on greater efficiency. The Agri-Tech Strategy does not provide a distinct vision for UK fresh produce, nor the Animal and Plant Health in the UK: Building our Science Capability white paper (UK Government 2013a, 2014a). The primary innovation support mechanisms that support entrepreneurs are the AHDB's horticultural wing, a number of research institutes such as NIAB EMR and Warwick Crop Centre, as well as private agronomic businesses. However, the performance of the fresh produce innovation system, its disaggregated barriers and opportunities for innovation, and how it fits into the wider picture of the UK AIS has not been well-described in the relevant literature.

This article seeks to identify fresh produce sector-specific systemic problems and propose targeted systemic instruments to counter such problems. It is organised as follows: the first section describes the theoretical framework guiding the study. The second section outlines the methodology employed in the study. The third section describes the systemic problems identified by the research. The final section places these problems in the context of the wider literature and matches systemic problems with suitable systemic instruments identified in this study and in existing literature.

\section{THEORETICAL FRAMEWORK}

An innovation system is a "network of organisations, enterprises and individuals focussed on bringing new products, new processes and new forms of organisation into use, together with the institutions that affect their behaviour and performance" (The World Bank 2006:vi-vii). The AIS approach is an increasingly applied framework for exploring change in agriculture (Klerkx, Aarts, and Leeuwis 2010) and belongs to a family of systems approaches that emerged in response to perceived inadequacies with 
the linear model of innovation that had until the late 1980s been dominant in innovation studies (Hall, Mytelka, and Oyeyinka 2006; Spielman, Ekboir, and Davis 2009). Whilst a linear view of innovation sees research as the primary driver of innovation (Hall et al. 2006), innovation systems frameworks perceive innovation as a process involving the co-evolution of technological and non-technological elements (Schut et al. 2015). In the agricultural sphere, new machinery, cultivars, agricultural inputs and practices are examples of technological change, whilst social and economic arrangements, such as new institutional environments and social norms, are examples of non-technological change. These changes take place across multiple levels, from field to farm to region (Klerkx et al. 2010; Schut et al. 2015). As such, innovation is as much about institutional change and social processes as the development of new technology (Röling 2009; Schut et al. 2014; Struik, Klerkx, and Hounkonnou 2014). In agriculture, innovation relies on the interaction between a group of heterogeneous actors, such as farmers, researchers, agronomists and advisors, processors, input suppliers and civil society (Brooks and Loevinsohn 2011; Hall 2007; Klerkx et al. 2010; Leeuwis 2004; Röling 2009).

Given the recent emphasis on innovation in the UK fresh produce sector, there is a need to understand how the technological, social, economic and institutional conditions of the sub-sector encourage or impede innovation. Factors that negatively influence the speed and direction of innovation processes are known as systemic problems (or systemic failures, barriers or weaknesses). One means to identifying systemic barriers is the functional-structural analysis. Although there are a number of dimensions to innovation system analysis, two previously separate but complementary approaches have been combined to build a comprehensive framework for understanding the dynamics of 
innovation systems (Hekkert et al. 2007; Kebebe et al. 2015; Klerkx, van Mierlo, et al. 2012; Wieczorek and Hekkert 2012).

Some authors have previously drawn a distinction between issues that occur at the functional and structural levels of the innovation system (blocking mechanisms and systemic problems, respectively). A functionalist view of innovation systems sees the system provide a variety of functions (outlined in Table 1) that can be performed to better or worse extents (Hekkert et al. 2007). Structures represent the landscape of the innovation system, being actors (individuals and organisations), institutions (rules and norms), interactions (relations between actors) and infrastructure (either physical or knowledge-based). Conveniently, Wieczorek \& Hekkert (2012) have developed a typology of systemic problems that links systemic problems to a structural element within one of the seven functions: 1) the presence/absence or capabilities of certain actors, 2) the presence/absence or quality of the institutional environment, 3) the presence/absence or quality of the interactions between actors and 4) the presence/absence or quality of the infrastructure.

\section{Table 1}

Functions of an innovation system (adapted from Turner et al. 2016)

\begin{tabular}{l|l}
\hline Function & Description \\
\hline Entrepreneurial activities & $\begin{array}{l}\text { Entrepreneurs use the potential of new knowledge, networks and } \\
\text { markets to create value (Klerkx and Leeuwis 2008b). Such activities } \\
\text { can also include lobbying and attempts to 'restructure' institutional } \\
\text { environments. }\end{array}$ \\
\hline
\end{tabular}




\begin{tabular}{|c|c|}
\hline Knowledge development & $\begin{array}{l}\text { Knowledge is considered a fundamental prerequisite to innovation } \\
\text { (Kebebe et al. 2015) and the ability to create new knowledge is a } \\
\text { vital component of an effective innovation system. Creation of new } \\
\text { knowledge is not restricted to the formal research establishment; } \\
\text { farmers and agro-businesses are also sources of new knowledge. }\end{array}$ \\
\hline Knowledge diffusion & $\begin{array}{l}\text { Diffusion of knowledge through networks is vital to further develop } \\
\text { and adapt innovations, to scale innovations 'up and out' and } \\
\text { enhance the "co-evolution of social, technological, institutional and } \\
\text { market changes" (Hermans et al. 2013; Turner et al. 2016). }\end{array}$ \\
\hline Guidance of the search & $\begin{array}{l}\text { The creation of a "vision" for the innovation system with which to } \\
\text { orientate other system functions is important. Shared meanings, } \\
\text { expectations and clear future vision can stimulate innovation by } \\
\text { reducing uncertainty and providing a sense of direction to innovation } \\
\text { processes (Mylan et al. 2015). }\end{array}$ \\
\hline Market formation & $\begin{array}{l}\text { New technologies can struggle against existing technologies and } \\
\text { resistance from the consumer and/or incumbent players. Creating } \\
\text { new, niche markets can stimulate innovation (Kebebe et al. 2015). }\end{array}$ \\
\hline Resource mobilisation & $\begin{array}{l}\text { The mobilisation of resources refers to the management of the } \\
\text { human and financial resources to undertake activities within the } \\
\text { innovation system (Hekkert et al. 2007). This includes funding for } \\
\text { research and subsidies for certain technologies for example, as well } \\
\text { as to attract appropriate expertise in innovation trajectories. }\end{array}$ \\
\hline Creation of legitimacy & $\begin{array}{l}\text { Legitimacy is necessary to counteract resistance to change inherent } \\
\text { in existing systems of production, trade and consumption. }\end{array}$ \\
\hline
\end{tabular}

By exploring the dynamic interactions that bring about innovation, it is possible to assess an innovation system against its supposed functions in a systematic manner to diagnose 
problems (see Kebebe et al. 2015; Turner et al. 2016). The functional-structural analysis provides the basis for relevant policy development and intervention at the system level, rather than at the level of its individual components (Bergek et al. 2008). These interventions are known as 'systemic instruments' and can take on a variety of forms, but are often focussed on stimulating interaction between key system actors through, for example, the joint foresight and 'vision' building (Smits and Kuhlmann 2004; Turner et al. 2016; Wieczorek and Hekkert 2012).

\section{METHODOLOGY}

The study employed an applied qualitative approach (Ritchie and Lewis 2010). As is common in AIS diagnostic work, semi-structured interviews were utilised to generate data (Turner et al. 2016). Semi-structured interviews permit the interviewer to pursue emergent themes during the interview and provide data of sufficient depth to explain social processes (Mason 1996). The sampling frame for participant selection was determined in part by the AIS framework (i.e. farmers, researchers and other system actors) and also by the limits of the fresh produce sub-sector. Sampling criteria were designed to maximise both geographical and professional diversity - this was done to capture as many voices as possible from a sector with a large variety of crop types and farming systems. Both purposive sampling (the selection of participants close to the topic of interest) (Palys 2008) and co-nomination sampling (researcher participants themselves nominate other participants) (Eide 2008) were used.

Ethical approval was granted to the project by the University of Warwick Biomedical and Scientific Research Ethics Committee (BSREC) before interviews commenced. A topic guide was developed that included five areas of inquiry: (i) the nature of innovation, (ii) 
the sources of innovation, (iii) enabling and disabling factors for change, (iv) communication in the sector and (v) challenges for the sector. In total, 32 interviews were carried out between June 2015 and January 2017, involving individuals from farm businesses (14), research (5), agronomy/consultancy (3), producer organisations (3), levy board and policy (3), supermarkets (2) and breeding companies (2). It is worth noting that several interviewees had prior experience in one or more of the categories listed here. The interviews, which lasted between 35-60 minutes, were recorded by Dictaphone and subsequently transcribed. NVivo 10 (for Mac) was used to organize the data for analysis.

The data analysis consisted of two stages: the initial reduction of data was carried out in accordance with Framework Analysis, an approach developed by Jane Ritchie and Liz Spencer in the late 1980s for large-scale policy work (Ritchie and Lewis 2010). The approach is suited to research that has specific questions, a limited timeframe, a predesigned sample (in this case, those involved in the UK fresh produce sector) and a priori issues - these are themes one can expect to emerge as a result of the characterisation of the problem under study, existing definitions and decisions made with respect to prior theory (Ryan and Bernard 2003; Srivastava and Thomson 2009). An initial coding framework was developed by open coding early interview transcripts, by which subsequent transcripts were indexed. Higher-level analytical themes were discovered through charting (reading across cases and down codes) (Srivastava and Thomson 2009), which are outlined in the section below. A functional-structural analysis was then conducted following a secondary literature review in order to match systemic instruments with identified systemic problems - the results of this process are summarised in Table 2 and expanded upon in the Discussion. 


\section{FINDINGS}

In this section, the main findings of the study are outlined, with specific emphasis on systemic problems. These problems are matched with systemic instruments in the Discussion. Quotations from participants (in italics) are provided to illustrate themes numbers alongside quotes indicate unique interviewee number.

\subsection{Innovation in the fresh produce sector}

\subsubsection{The importance of entrepreneurialism}

The study found there was a perception that the fresh produce sector was characterised by a strong entrepreneurial spirit and innovativeness:

"... more in keeping with a typical industrial business, [fresh produce businesses] see innovation and intellectual property as an opportunity to differentiate themselves in the market place." - Producer association representative (8)

"Innovation as I see it is hugely important. It's a mainstay of our own business, and it needs to be the mainstay of any horticultural business." - Field vegetables grower (11)

"Innovate or die" - Potato grower (27)

The establishment of polytunnels as the primary growing system for several categories of British soft fruit was considered by many to epitomise this entrepreneurial spirit, indicted by the high number of participants who cited this as the most transformative innovation of recent decades. However, innovation across a range of areas - product, process, infrastructure and marketing - were also cited as important to the sector. 
Something that growers must contend with is what participants described as the prevailing "defensive" innovation culture, where only cost-cutting (rather than more transformative) innovation is rewarded:

“... the supermarkets are always pushing each other forward and the view from elite leaders of large consolidated businesses in the industry, they were saying 'yes that does drive innovation, but it's actually quite a defensive, quite a limited sort of innovation." AHDB representative (31)

"A lot of the innovation on farm that I see in fresh produce is borne about by necessity, because the farmer says 'if I don't do this, I'm gonna go out of business. "' - Supermarket representative (29)

“... most growers [are] running faster and faster and faster to try and stay in the same place..." - Agronomist (9)

The cause of this defensive culture was held to be competition between large multiple retailers (see below). In contrast to the systemic nature of the problems for growers observed here, personal facilitators of change were emphasised by farm business representatives themselves, such as the willingness to interact with others and seek out information. Growers often rely on personal and professional networks to solve problems and learn about new ideas, maintaining close, trustful relationships with key scientists and institutions, as indicated by several growers:

"I go direct to [nearby agricultural research institute] because we do have these close contacts with the scientists there, [and] sort of say 'what do you know about this? What can you do about it?'” - Soft fruit grower (23) 
"The bulk of our innovation will come from a small number of people who we have personal trusting relationships with... so we work very closely with them and we value what they have to say for themselves and so we actually will follow their lead." - Field vegetable grower (21)

In addition to following the lead of scientists, other champions also influence change in the sector according to a number of participants:

"There are some inspirational people around." - Field vegetable grower (1)

"I think people are very, very important in this. You have to have your captains. Your champions." - Researcher (6)

These observations serve to highlight the importance of entrepreneurs for innovation processes in the fresh produce sector, but also indicate that innovation has taken on a "defensive" character. Entrepreneurs also follow the lead of trusted researchers and other champions.

\subsubsection{Retailer power}

A contradiction frames debates about innovation in the UK fresh producer sector, which was described by some participants as thriving on newness through product differentiation and by others as suffering from a culture of conservatism driven by supermarket retailers, whose buying policies are primarily focussed on cost reduction and consistency:

"I would have to be honest and say that the retailers can be a barrier. The retailer, all they want is consistency and cost reduction." - Supermarket representative (29) 
Negative, sometimes exploitative supplier-customer relationships and diminishing returns to the grower were perceived to have led to some of the most significant barriers to innovation in the sector:

"Supermarkets... we are facing one of the biggest challenges we've ever faced and its price wars." - Agronomist (26)

"Today's greatest challenge is return to the producer." Researcher (19)

"It's this constant battle with the retailers who are constantly pushing down on price, constantly looking for more efficiency, scrutinizing the level of profit you are making out of them." - Technologist (9)

One large farm business discussed "hiding" innovation from their customers for fear of further downward pressure on prices. However, other participants had success in partnering with their customers to establish new product lines, whilst others called for collaborative supply chain management. Supermarket representatives themselves acknowledged that their focus on consistency and cost reduction created a barrier to innovation (as indicated above) but also that working with suppliers to develop new products was a valuable exercise:

"... we invest a lot of time working with the very early stages of product development, which in produce is the breeders, the nurseries... they are often asking: 'what do you think the market will want in five to ten years time?' Rather than ... expecting everything to come to you." - Supermarket representative (33)

It follows that innovation support could be improved by fostering more supportive and respectful commercial relationships in the sector. 


\subsubsection{The influence of producer organisations}

It was suggested by many participants that the fresh produce sector has a strong reliance on innovation originating outside the UK, with significant emphasis placed on Dutch and Anglosphere innovation:

"... if you want to see innovation- you probably want to go to Holland to see how all that works, to see how they are so successful with their innovation, 'cos that's where a lot of it comes from isn't it?" - Potato grower (27)

At the same time, participants noted the importance of trans-boundary partnerships between domestic POs and foreign businesses. These 'strategic partnerships' often involve the exchange of novel, proprietary plant lines ("genetics") and expertise. A number of large UK farm businesses and POs boast overseas production sites in other parts of Europe and sub-Saharan Africa, permitting access to local formal and informal knowledge and year-round experimentation with particular plant lines, as indicated by a grower in Scotland:

"We have an alliance with a Spanish company... the Spanish winters are very similar to [British] autumns, so we actually get two years in one." - Soft fruit and vegetable grower

It was also found that POs and other large fresh produce businesses co-fund research projects and support early-career researchers, which enables them to influence research agendas and monitor relevant scientific outputs. These organisations use a variety of mechanisms to keep their grower base in touch with the latest agronomic, technological and market developments; this includes in-house agronomy, annual conferences and study tours (often with their American or European partners): 
“... I mean [producer organisation] have had [study tours] to Mexico, to Chile, Argentina, the States, Spain and Holland..." Soft fruit grower (23)

However, the ability of larger businesses, including POs, to influence (nationwide) research agendas was subject to questions of fairness:

“... let's say [you have] ten growers of lettuce, one of them is hugely dominant, while the innovation is being done for them and the others look and say 'well we can't implement that because we don't have that scale."'-Researcher (19)

A further issue for these organisations is 'strong network failure', whereby knowledge is locked 'out' as much as 'in', an issue described by a grower belonging to a large UK POs:

“... people are becoming very focussed into their groups. You lock yourself out of other things. But, you know, it was governmental bodies that were all to do with that in the past - so it was open to everybody. Whereas now, if you have a good idea you keep it to yourself or keep it in the group." - Soft fruit grower (25)

It is evident that POs now play a significant role in the innovation process, particularly as nodes for overseas innovation - they have also contributed to a more 'closed' innovation system.

\subsubsection{Policy and market}

It was found that policy - particularly at the pan-European level - also shapes the trajectory of UK agricultural innovation. The withdrawal of certain crop protection products was a common topic of concern: 
"... the government has an underlying strategy of sustainable growth in horticulture. That seems to be at odds with the European Commission's- the fervor in which they're putting into removing a lot of the active ingredients... I would also like to see the same amount of fervor being placed into supporting research and activity around integrated pest management." Supermarket representative (29)

"We've lost a huge percentage of our active ingredients in the last ten years." - Field vegetables grower (1)

The cost of product registration in Europe was also noted by some participants as deterring investment in new crop protection products. The relative size of the UK fresh produce sector also appears to deter significant investment and relegates it to off-label or "minor use" of crop protection products designed for the arable market, as indicated by an ornamental plant grower:

"If you need to spray something on potatoes, then it's worth the chemical company producing the thing. If you need to spray it on hardy Geraniums, they're never ever going to make any money out of that." - Ornamental plant grower (17)

Another described the fresh produce sector as relying on the "crumbs" of arable sector crop protection products. There was also a notable disdain for subsidies across the sector, from retailer representatives to small growers, as it was suggested these diminish innovation in farming:

"I think the greatest thing that holds back innovation in this country... is the subsidies that [it] enjoys." - Supermarket representative (29)

"It stifles innovation..." - Field vegetable grower (16) 
In summary, the structural conditions of the fresh produce sector exacerbate EU policy towards the regulation of active ingredients - agricultural subsidies also prove unpopular across the sector.

\subsection{Fragmentation}

\subsubsection{Lack of research coordination and foresight}

A discernable lack of unifying research coordination was cited as an example of vertical fragmentation:

"... the research in the UK is too disjointed... everybody's doing their own thing and there's nothing actually coordinating it." - Supermarket representative (29)

Fragmentation also occurs along sub-sectoral lines due to the diversity of crops within the sector and their specific research needs:

“We've fragmented definitely on sector lines in fresh produce... because in fresh produce the requirements are so different between growing a tomato and growing lettuce." (19)

"Not everybody's been aware of it, quite often we might be developing technology that's applicable to a whole range of crops but one panel will be doing it, but the other panels are blind to it, they haven't shared their costs, and then they don't share the learnings."

Some participants also suggested that short-term thinking - exhibited in levy board steering panels - prevented steps being taken to address growing problems (such as the withdrawal of certain crop protection products or long-term sustainability): 
"The one problem with that is that the growers who sit on those panels they're thinking about today's problems: 'what's my problems this year?', 'what am I struggling with this year?' and not thinking about 'what are my problems gonna be in ten years time?'”Field vegetables grower (1)

The transition from public to private of the formerly-public UK extension service (ADAS) was also cited as having impacted the translation of agricultural research into practice:

"You know, we got rid of ADAS, the big gap is the translation of research into practice... the extension. That's still a massive blackhole." Field vegetables grower (1)

“... so we haven't got the join-up with the basic science anymore, into the applied science, in the applied science you've got all the contractors separated from each other, and the pull-through doesn't look terrible brilliant." AHDB representative (31)

These observations provide evidence for (vertical) fragmentation in the sector. The susceptibility of research agenda-setting mechanisms to reactivity and lack of mechanisms to transfer research into practice also represent systemic problems for the sector.

\subsubsection{Communication}

A number of factors were described by participants as constituting barriers to effective communication. The transition from a public extension model, for example, was cited as having limited opportunities for interaction:

"In horticulture, [innovation] is people talking to one another... funding and support from research institutes has just been stripped away. I think that's something the funding bodies don't understand, we've lost a lot of support and facilities." - Seed supplier (30) 
Intense competition between firms was thought to limit the amount of knowledge shared between businesses and other organisations (i.e. horizontal fragmentation), even when the sharing of such knowledge may be valuable to both parties. The communication of research results was likewise brought into question, it being suggested by a number of participants that researchers themselves were not necessarily best placed to deliver such information or understood on-farm practicalities:

"I think that they talk different languages." - Producer association representative (8)

"They probably don't understand all the constraints and what they see is what a good idea it probably is, but what they don't understand is the knock-on effects or why it's not practical." - Field vegetables grower (28)

However, these views should be contrasted with examples of positive relationships between industry and researchers described above. A range of industry-focussed projects and innovation platforms have also been established in recent years (see below), which may serve to counter this trend. It was observed that the AHDB can struggle to demonstrate the value of its research, particularly where sources of knowledge are masked by appropriation at point of delivery, as described by a potato grower:

“... by the time it goes to the grower it's not carrying an AHDB brand it's carrying a Scottish Agronomy brand." - Potato grower (22)

The gradual loss of expertise through retirement (without adequate succession planning) was cited as a barrier to the spread of the knowledge that individuals and institutions may hold. A secondary effect associated with the loss of expertise is the duplication of existing research, which several researchers had seen during their careers: 
"I see things that are being done again that I thought 'well, we did that twenty years ago'... the papers aren't necessarily in the databases when you search them." Researcher (7)

A clear perception that the sector has become more 'closed' is evident. How researchers communicate with industry and the succession of researchers were also cited as systemic problems.

\subsubsection{Divergent innovation agendas}

Divergent innovation agendas, borne from differences in business size, crop types and the relative size of each sub-sector, represent a challenge for innovation support services in the fresh produce industry:

“... so one project we've got, [looks] at field mapping and looking at precision farming. If you went to one of the smaller businesses, they couldn't use it." - Researcher (19)

"The other thing with our industry is that the UK is really quite small as a market. So for someone to design a baby leaf harvester in the UK, will be really wasting his time. 'cos he won't be able to sell any machines." Salad leaf grower (14)

It was also found that not all would-be participants have equal access to the mechanisms for capturing the research needs of industry - differences in material resources, time and staff permit larger companies to influence research agendas to a greater extent than smaller farm businesses. The deployment of dedicated technologists by large businesses and POs is an example of this unevenness: 
"... so if you take [company], they employ people who are highly qualified

technical people... and they go 'round and they're really good at foraging, so

they look at all the technologies worldwide..." - AHDB representative (31)

In summary, a degree of fragmentation can be identified across the sector with respect to: research coordination, communication and divergent innovation agendas between crop types and business or market size. How these (connected) systemic problems might be remedied is dealt with below.

\subsection{Positive interfaces}

The study found several mechanisms that served to support innovation in the fresh produce sector at a systemic level. A number of past and current innovation platforms, for example, have also brought together actors from across the sector to target specific problems and provide a pathway for research to have impact. The SCEPTRE, HIP (Horticulture Innovation Partnership) and HAPI (Horticulture and Potato Initiative) projects were each cited as valuable initiatives and the HortLINK scheme, in particular, for translation of research into practice:

“... what [HortLINK] was doing was giving a vehicle for what had been funded in terms of blue sky [research] to get that carry-through to the market place and that it didn't get lost." Producer organisation representative (2)

It was found that grower groups, which are often crop-specific (AHDB-led) or customerspecific (retail-led), also provide platforms for agronomists, scientists and growers to discuss research needs and communicate scientific advances. The SCEPTRE and SCEPTREplus projects provide a platform for the identification of 'gaps' in the 
horticultural crop protection portfolio (a response to the loss of certain active ingredients in the EU). These initiatives represent an opportunity to orientate research around integrated pest management techniques, organic farming and other crop protection systems such as robotic mechanical weeding:

"So for instance [one of our] projects which we're doing is looking at novel weed control systems... we currently have a massive problem with weed control in our crops where the alternative is hand weeding, which is expensive and difficult to do. So there's a big opportunity if we can come up with solutions to that there's a significant commercial driver within our business to make that happen." Field vegetable grower (21)

The indication that these platforms are valued by participants also provides a basis for the development of systemic instruments to counter systemic problems (outlined in Table 2). 


\section{Table 2}

2 Systemic problems in the UK fresh produce sector: each problem is categorised by innovation system function. Systemic problems belong to 3 one structural element (actor, interaction, institution and infrastructure) and can be described by their presence/absence and capability/quality.

4 Suggested systemic instruments are proposed based on primary research and existing literature - example systemic instruments are given $5 \quad$ where determined by this research.

\begin{tabular}{|c|c|c|c|c|c|}
\hline System function & Structural element & Problem "type" & Description & $\begin{array}{l}\text { Suggested systemic } \\
\text { instrument }\end{array}$ & $\begin{array}{l}\text { Selected } \\
\text { examples of } \\
\text { systemic } \\
\text { instruments }\end{array}$ \\
\hline \multirow[t]{2}{*}{$\begin{array}{l}\text { Entrepreneurial } \\
\text { activities }\end{array}$} & Interaction & Quality & $\begin{array}{l}\text { Power asymmetry between } \\
\text { suppliers and customers }\end{array}$ & $\begin{array}{l}\text { New forms of supply-chain } \\
\text { governance }\end{array}$ & $\begin{array}{l}\text { Groceries Code } \\
\text { Adjudicator }\end{array}$ \\
\hline & Actor & Capability & $\begin{array}{l}\text { Some actors have insufficient } \\
\text { resources to innovate }\end{array}$ & Venture capital & $\begin{array}{l}\text { EU's fruit and } \\
\text { vegetable regime } \\
\text { funding (via } \\
\text { producer } \\
\text { organisation) }\end{array}$ \\
\hline
\end{tabular}




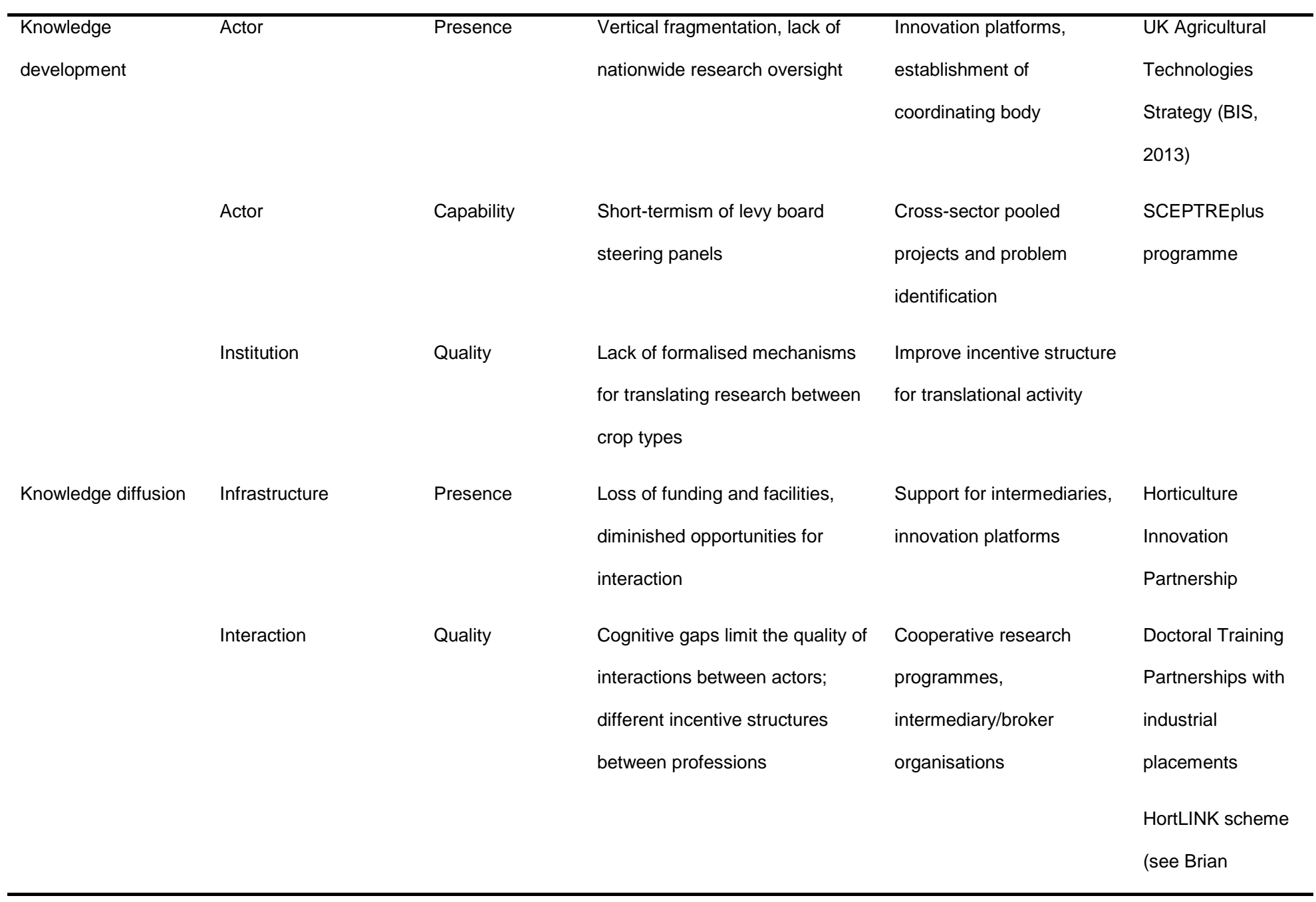




\begin{tabular}{|c|c|c|c|c|c|}
\hline & & & & & $\begin{array}{l}\text { Jamieson \& } \\
\text { Associates, 2008) }\end{array}$ \\
\hline & Interaction & Quality & $\begin{array}{l}\text { Horizontal fragmentation, strong } \\
\text { network failure }\end{array}$ & $\begin{array}{l}\text { Innovation platforms } \\
\text { targeting common } \\
\text { problems }\end{array}$ & $\begin{array}{l}\text { SCEPTREplus } \\
\text { programme }\end{array}$ \\
\hline & Infrastructure & Quality & $\begin{array}{l}\text { Loss of expertise and specialist } \\
\text { knowledge due to inadequate } \\
\text { knowledge-handling practices } \\
\text { and succession planning }\end{array}$ & $\begin{array}{l}\text { Centralised research } \\
\text { databases }\end{array}$ & \\
\hline \multirow[t]{2}{*}{$\begin{array}{l}\text { Guidance of the } \\
\text { search }\end{array}$} & Actor & Capability & $\begin{array}{l}\text { Lack of a national steering } \\
\text { mechanism to guide AIS } \\
\text { functions }\end{array}$ & $\begin{array}{l}\text { Consensus development } \\
\text { conferences, road- } \\
\text { mapping }\end{array}$ & \\
\hline & Interaction & Quality & $\begin{array}{l}\text { Unequal participation in } \\
\text { guidance of the search activities, } \\
\text { some voices not heard }\end{array}$ & $\begin{array}{l}\text { Support for intermediary } \\
\text { organisations }\end{array}$ & \\
\hline Market formation & Interaction & Quality & "Defensive" innovation culture & $\begin{array}{l}\text { Incentives for retailer } \\
\text { differentiation strategy }\end{array}$ & \\
\hline
\end{tabular}




\begin{tabular}{|c|c|c|c|c|c|}
\hline $\begin{array}{l}\text { Resource } \\
\text { mobilisation }\end{array}$ & Institution & Quality & $\begin{array}{l}\text { Research funding is divided by } \\
\text { sub-sector, preventing coherent, } \\
\text { industry-wide, cross-cutting } \\
\text { research }\end{array}$ & $\begin{array}{l}\text { Cross-sector scoping } \\
\text { studies, investment in } \\
\text { formalised translation } \\
\text { mechanisms between crop } \\
\text { types }\end{array}$ & \\
\hline & Actor & Capability & $\begin{array}{l}\text { Regulation blocks use of certain } \\
\text { crop protection products and } \\
\text { discourages their registration in } \\
\text { Europe }\end{array}$ & $\begin{array}{l}\text { Advocacy coalitions } \\
\text { /lobbying, innovation } \\
\text { platforms for alternative } \\
\text { products/scenario } \\
\text { development }\end{array}$ & $\begin{array}{l}\text { SCEPTREplus } \\
\text { programme }\end{array}$ \\
\hline \multirow[t]{2}{*}{$\begin{array}{l}\text { Creation of } \\
\text { legitimacy }\end{array}$} & Interaction & Quality & $\begin{array}{l}\text { Lack of trust between suppliers } \\
\text { and retail customers }\end{array}$ & Retail-led grower groups & \\
\hline & Interaction & Quality & $\begin{array}{l}\text { Researchers not rewarded for } \\
\text { engagement with industry, lack } \\
\text { of mutual understanding/trust }\end{array}$ & $\begin{array}{l}\text { Cooperative research } \\
\text { programs }\end{array}$ & $\begin{array}{l}\text { Doctoral Training } \\
\text { Partnerships with } \\
\text { industrial } \\
\text { placements }\end{array}$ \\
\hline
\end{tabular}




\section{5. DISCUSSION}

8 The analysis identified several important themes concerning the structure of the UK AIS,

9 including fragmentation, power asymmetry between retail suppliers and customers and

10 the importance of producer organisations to innovation processes. These findings are

11 discussed in more detail below, with systemic problems and proposed instruments

12 matched to each system function as summarised in Table 2.

\section{$13 \quad 5.1$ Entrepreneurial activity}

14 Hekkert et al. (2007) state that the presence of a strong entrepreneurial base is a signal 15 of innovation system health. In the fresh produce sector, entrepreneurialism is essential 16 in a competitive market and by most accounts is providing the sector with new products, 17 new growing systems and improved efficiency. However, two primary systemic problems 18 were identified that influence entrepreneurial activity. The first relates to the power 19 asymmetry that exists between suppliers (growers) and customers (predominantly 20 supermarkets).

21 The asymmetry described in this study represents a systemic problem that transcends 22 the network or interaction failures outlined by Weber \& Rohracher (2012), such as strong 23 network failure. It can instead be described as a problem of interaction quality between 24 supplier and customer. It has been suggested that power imbalances in retail markets 25 are not necessarily an impediment to successful business arrangements (Hingley 2005). 26 However, participants noted that the 'price wars' between retailers, manifested in their 27 focus on cost and consistency, has led to a "defensive" innovation culture in the sector: 28 Roling (2009:87) calls this the "innovation treadmill" and notes that, because farmers 
29 cannot hold onto the rewards of their productivity gains, the treadmill leads to lower 30 prices (as participants described in the form of shrinking returns to growers). Alston et 31 al. (1997) also find that in situations of oligopony or oligopsony, research benefits accrue 32 to the larger processors - this may be reinforced by the uneven influence of larger firms 33 on setting the sectoral research agenda (see below). New forms of supply chain 34 governance are required to mitigate the adversarial attitude amongst fresh produce 35 suppliers and their customers, of which the establishment of the 'Groceries Code 36 Adjudicator' is one example, and improve the distribution of the benefits of innovation 37 (Revoredo-Giha et al. 2012).

38 The second systemic barrier for entrepreneurs specifically affects smaller producers. 39 Whilst there is nothing to say that all system actors should follow the same technological 40 trajectory (Weber and Rohracher 2012), the ability of firms to leverage human and 41 financial resources - and determine sectoral research agendas - is strongly dependent 42 on the size of the business. Companies incapable of leveraging these resources exhibit 43 capabilities failure; smaller firms risk being 'locked into' existing technologies (Klein 44 Woolthuis, Lankhuizen, and Gilsing 2005; Klerkx and Leeuwis 2009) and several 45 participants expressed concerns that the gap between larger and smaller firms was 46 growing with respect to innovation. Improving the availability of venture capital may 47 counter capability failures, as proposed by Turner et al. (2016); several participants in 48 this study were able to access funding through the European Union's Fruit and 49 Vegetable Regime via POs. The scheme matches fifty percent of pooled PO funding to 50 facilitate innovation across a number of areas. As such, systemic instruments that help 51 producers access existing funding are preferential. 


\section{$52 \quad 5.2$ Knowledge development}

53 A key systemic problem affecting the knowledge development function of the fresh

54 producer sector innovation system is vertical fragmentation. A lack of national

55 coordination has led to a situation in which a number of organisations undertake

56 research programmes with little or no coordinated oversight and in the name of different

57 innovation agendas. In turn, fragmentation can lead to the unnecessary duplication of

58 research by more than one group (also observed by Sutherland et al. 2013 in the UK

59 context). Fragmentation is not unique to the sector, but a characteristic of the AIS in

60 several European countries (Hermans et al. 2015; Turner et al. 2016). An issue of this

61 nature can be cast as either a problem of capability (none of the existing institutions are

62 able to coordinate action at the desired level or have such a mandate) or presence (no

63 organisation with such a mandate exists). The Agri-Tech Strategy provides an example

64 of a plan to better coordinate nationwide research, albeit with a normative focus.

65 However, in an increasingly internationalised landscape, the notion of limited, national

66 visions stands in contrast to the increasingly globalised nature of the sector (and other

67 innovation systems) (Metcalfe 2007). Science and Technology Forecasting (STF) is one

68 means of determining longer-term science and innovation policy (Meulen, de Wilt, and

69 Rutten 2003). Turner et al. (2016) suggest 'consensus development conferences' can

70 provide a means of overcoming the horizontal and vertical fragmentation that

71 exacerbates heterogeneous innovation agendas; yet this leaves the question of how to

72 engage those individuals or firms that lack the capability to partake in such events 73 unanswered. 
74 AHDB steering panels provide relatively quick, grower-led problem identification at, it

75 was claimed, the expense of more strategic, cross-sector problem identification. Some 76 participants suggested that short-term thinking prevented steps being taken to address 77 growing problems (such as the withdrawal of certain crop protection products), an issue 78 of actor capability (see also Hermans et al. 2015). Cross-sectoral initiatives designed to 79 pool resources for industry-wide problems could be an effective tool to orientate future 80 research, an option recognised by the AHDB in the form of the SCEPTREplus 81 programme that targets this issue.

82 The systemic problems associated with research translation can be classed on the one 83 hand as market failure: the knowledge market created by the privatisation of public 84 advisory services has not led to the development of appropriate mechanisms to carry 85 out this task. On the other, it is a problem of capability: institutions charged with 86 provisioning and delivering research activities have not developed robust mechanisms 87 for systematically capturing the value of new knowledge. Instead, these tasks fall on 88 individuals who are able to match the needs of growers with existing knowledge (in the 89 case of agronomists) or those who perceive the value in translating existing knowledge 90 into new avenues of interest (in the case of scientists). Although relatively little research 91 has been undertaken with respect to research translation in the agri-food sphere, 92 Wamae et al. (2011) find fragmentation to be a compounding issue (see also Pollock 93 2012). Improving academic incentive structures may stimulate and reward translational 94 activity. Certain facilities developed by the National Institutes of Health $(\mathrm{NIH})$ in the 95 United States, such as the National Centre for the Advancement of Translational 96 Science (NCATS, established in 2011), have the express goal of taking basic science 
97 discoveries to the 'bedside' and this model could form the basis for an agricultural

98 research equivalent (Menary 2015).

99 Cross-border business partnerships between larger fresh produce businesses and POs

100 in different countries exemplify the increasingly globalised nature of knowledge

101 production and the spread of innovation through formalised networks or communities of

102 practice. The globalisation of knowledge has been the subject of significant academic

103 work, but this is less evident with respect to innovation within the organisations

104 themselves and through their cross-border partnerships. As the search for knowledge

105 has taken on a worldwide dimension, the locus of innovation has shifted from individual

106 firms to wider, distributed networks in which they sit (Herstad, Aslesen, and Ebersberger

107 2014) - an observation supported by this study, which suggests that industrial sectors

108 remain vital prisms through which to understand innovation systems.

\section{$109 \quad 5.3$ Knowledge diffusion}

110 Several systemic problems affect knowledge diffusion in the sector. The UK, and

111 England in particular, has seen a concentration of dedicated research institutes over the

112 last thirty years (Hermans et al. 2015), which was perceived to have diminished

113 opportunities for interaction. Innovation platforms (IPs) provide a means to bring different

114 stakeholders from a particular sector together to create a support network for

115 transformative change (Hounkonnou et al. 2012) - IPs such as HAPI and HIP were

116 recognised as useful platforms for orientating fresh produce sector research activities. A

117 further strength of IPs is providing a platform for 'champions' - who were cited as key

118 drivers of fresh produce innovation - to influence others and promote new ideas (Klerkx

119 et al. 2013). 
120 Another problem stems from what Klerkx \& Leeuwis (2009:850) call "cognitive gaps", in

121 which actors from different institutional backgrounds struggle to learn together due to 122 their respective norms, values and incentive structures. It is these differences that some 123 participants claimed prevented researchers and farmers from speaking the same 124 language, suggesting that researchers are not always best-placed to engender 125 knowledge exchange. A problem of this type is one of quality: interaction does occur but 126 is hampered by lack of mutual understanding. However, this should be contrasted with 127 the trustful, productive farmer-scientist relationships many in the sector described as 128 having (see above). Industry-focussed Doctoral Training Partnership (DTP) 129 programmes, which often include industrial placements, represent one mechanism to 130 foster better communication between researchers and the agricultural industry.

131 As Klerkx et al. (2012) note, strong network failure can lead to myopia and blocks new 132 ideas from outside the network and collaboration with others - this issue was raised with 133 respect to POs, which, despite providing numerous benefits to their members, reflecting 134 insularity and horizontal fragmentation. Conversely, weak network failure signals 135 networks that are not connected to cycles of learning and innovation. A balance between 136 openness and closure, trust and contacts is thus a goal for innovation networks (Klerkx, 137 van Mierlo, et al. 2012). Innovation platforms targeting common problems, such as the 138 SCEPTRE programmes, could present an opportunity for POs to share knowledge.

139 A potential solution to the (infrastructural) problem of inadequate succession planning 140 and duplication of research is to establish or improve standardised databases for better 141 storage and retrieval of past research (Klerkx and Proctor 2013).

142 A further phenomenon related to the knowledge diffusion function is how the multiple 143 sites of production that large produce businesses and POs maintain in different regions 
144 facilitate learning and experimentation with new plant varieties. Given that the

145 development of new knowledge through practice - 'know-how' or 'experience-based-

146 knowledge' - is key for producers (Dougherty 2004), the exchange of knowledge

147 between local researchers and highly-mobile growers, agronomists and technologists,

148 illustrates the importance of learning in innovation processes (and how these are

149 influenced by systemic factors) (Kilelu, Klerkx, and Leeuwis 2014). Grower study tours,

150 organised through POs or by the AHDB likewise represent an interesting example of

151 agricultural social learning that has heretofore gone unreported in the relevant academic 152 literature.

\section{$153 \quad 5.4$ Guidance of the search}

154 Several systemic problems prevent the establishment of a clear vision for the fresh

155 produce sector, which is a key component of the guidance of the search function of 156 innovation systems (Kebebe 2018). The lack of mechanisms to 'steer' AIS functions, for

157 example, prevents the orientation of the various functions around achieving common

158 goals; divergent innovation agendas add a further obstacle to developing a coherent 159 vision for the sector, which as observed above is marked by large variations in business 160 sizes, crop types and subsequent research needs (also observed by Turner et al. 2016

161 in New Zealand). Consensus-development conferences can facilitate the development 162 of a coherent vision for the sector (Turner et al. 2016). In the UK dairy sector, road163 mapping has been used to successfully orientate the sector around specific goals (like 164 improved water efficiency and reducing on-farm emissions) and providing "socio165 cognitive coordination" (Mylan et al. 2015). Such roadmaps could be designed through 
166 stakeholder-led dialogue in either specific fresh produce sub-sectors or for sector-wide

167 problems (such as soil health or the use of artificial agricultural inputs) by the AHDB.

168 There is also evidence of "progressive client bias", in which knowledge-based 169 organisations focus on businesses that already possess the means to innovate; the 170 ability of larger farm businesses and POs to influence research agendas distorts the 171 guidance of the search function by promoting their priorities through the organs meant 172 to capture the needs of the entire sector (Klerkx et al. 2006; Klerkx and Leeuwis 2008b). 173 Here, this is described as a problem of interaction quality: support for intermediary

174 organisations that can capture the needs of smaller producers is one mechanism by 175 which this problem might be countered.

\section{$176 \quad 5.5$ Market formation}

177 Market formation is not a particularly weak function of the fresh produce industry 178 innovation system, but it does suffer from the same systemic problem described for 179 entrepreneurial activities: a "defensive" culture of innovation. Sodano \& Hingley (2009) 180 argue that product differentiation is a key strength of the fresh produce sector, through 181 provenance, standards (organic, fair trade) and de-seasonality, echoing some 182 participants in this study who claimed that the sector employed a more industrial 183 approach to product development. However, retailers can appropriate the advantages 184 of differentiation by maximising their own profit - this limits opportunities for new market 185 formation if retailers do not take a lead in new product development or undervalue it 186 (Esbjerg et al. 2016; Sodano and Hingley 2009). Given that supportive commercial 187 relationships have been found to be more conducive to innovation both in the relevant 188 literature and in this study, there is an opportunity for retailers to develop new markets 
189 by better incentivising their differentiation strategies and supporting their suppliers in 190 adopting new technologies (Mylan et al. 2015; Revoredo-Giha et al. 2012).

\section{$191 \quad 5.6$ Resource mobilisation}

192 Resources, such as human and financial, capital are vital components of an innovation

193 system. Funding for R\&D, whether mobilised by industry consortia or through public 194 sources, is one measure of this function (Hekkert et al. 2007). The sub-sectoral division 195 of funds prevents resources being mobilised to target cross-sector issues, however, 196 which can be described as a systemic problem of institutional quality. Scoping studies 197 targeting mutual issues and development of formalised processes for translational 198 research between crop types could represent initial steps to tackle this issue.

199 The relative size of the UK fresh produce sector appears to deter significant investment 200 and relegates it to off-label or "minor use" of crop protection products designed for the 201 arable market. Certain European Union-wide regulation of crop protection products (and 202 the costs of registration and testing these products in Europe) was also perceived to 203 deter investment in agriculture. The threat of withdrawal for the minor use of crop 204 protection products (see Villaverde et al. 2014) corresponds to an institutional problem 205 related to the quality of the regulations that prohibit their use and makes them 206 prohibitively expensive to register for such use. "Brexit" may offer an opportunity for the 207 UK to change the approval mechanisms for these products, pending future trading 208 relationship with the EU and providing an 'advocacy coalition' of concerned parties can 209 be convened (Klerkx et al. 2010; Turner et al. 2016). 


\section{$210 \quad 5.7$ Creation of legitimacy}

211 The decline of social capital and trust in European AIS may pose a significant barrier to 212 establishing new technological trajectories. In the fresh produce sector, this decline is

213 most apparent between suppliers and their retail customers. As supply chain leaders, 214 retailers bear significant responsibility for legitimising new technologies and practices.

215 Retailer-led agronomy groups that bring producers and scientists together are one 216 avenue by which supermarkets can create legitimacy for new technological trajectories.

217 It was also noted that researchers are not necessarily rewarded for engagement with

218 industry, nor do all researchers command the respect of the farming community - a

219 problem of interaction quality that undermines the ability of research to establish new 220 technologies. Cooperative research programmes that link scientists and industry can 221 mitigate this problem, such as near-market AHDB research projects and DTPs.

\subsection{Recommendations, limitations and further research}

223 It is recommended that those institutions tasked with matching the supply and demand 224 of agricultural knowledge focus on systemic facilitation as a means to improve overall 225 innovation system performance. The evidence presented here points towards the need 226 to better - and more equitable - models of interaction between specific groups, whether 227 commercial relationships or the translation of research into practice. However, it should 228 be noted that one of the limitations of the functional-structural analysis and the approach 229 employed in this study is the 'problematisation' of the AIS: although the findings 230 demonstrate a range of systemic problems, it is clear that the fresh produce sector 231 remains innovative and competitive even as innovation support services adapt to the 
232 post-public extension environment through various initiatives. Whilst the land area given

233 over to horticultural production has declined, its output and value have continued to rise,

234 suggesting a degree of success in the functioning of the sectoral innovation system

235 (Menary 2018). A weakness of the innovation systems approach is a disregard for the

236 directionality of innovation, that is, although technology- or sector-specific policy issues

237 might be addressed, less attention is paid to guiding technological innovation in a 238 particular direction (i.e. towards more environmentally sustainable configurations)

239 (Weber and Rohracher 2012). Other frameworks, such as the multi-level perspective,

240 place greater emphasis on such transitions and could prove a useful framework for

241 understanding these processes in the fresh produce sector.

242 This article has shown that sectoral analyses remain important within the wider AIS -

243 power asymmetries, the globalisation of agricultural knowledge and the role of POs

244 being distinct aspects of the UK fresh produce sector but also interesting contributions

245 to the AIS literature. Further research might explore what diverse production sites and

246 study tours mean for the development and spread of agricultural knowledge.

\section{6. CONCLUSION}

248 There are a number of system problems in the UK fresh produce sector, many of which 249 stem from the ongoing transition to a demand-driven, pluralistic advisory service. These 250 problems can be matched with systemic instruments that have been identified in this 251 study and in the relevant literature. Most are related to systemic facilitation 252 encouraging the formation or better function of networks. Significant responsibility rests 253 with retailers, which command asymmetric supply chain power but have created a 254 "defensive" innovation culture through a constant downward pressure on prices. The 
255 decline in social capital around Europe is evident in the relationship between suppliers

256 and customers, yet it is this relationship that can establish new technological trajectories.

257 As such, retail-led grower groups are a means to foster trust and support producers.

258 The use of consensus-development conferences and road-mapping, innovation 259 platforms and cross-sector projects can provide a level of cooperation and coordination 260 for an increasingly closed and fragmented sector; examples of these exist either in other 261 agricultural sectors, or in the fresh produce sector itself. SCEPTREplus, for example, 262 fulfils these aims by targeting common pest control problems.

263 The importance of producer organisations in the innovation process has been 264 demonstrated. In particular, the use of in-house agronomy, study tours and overseas 265 sites of production represent previously unexplored aspect of agricultural innovation 266 processes, which may warrant further research. Likewise, there is a need to understand 267 how the systemic instruments proposed here facilitate or impede wider transitions within 268 the agricultural system.

\section{ACKNOWLEDGEMENTS}

270 We thank the AHDB and University of Warwick for funding this project. Likewise, we 271 appreciate the generosity of the participants for their time, reflections and hospitality.

272 Funding: this study was funded by the Agriculture and Horticulture Development Board 273 and University of Warwick (project no: CP-131).

274 Declarations of interest: none. 
REFERENCES

276

277

278

279

280

281

282

283

284

285

286

287

288

289

290

291

292

293

294

295

296

297

298

299

300

301

302

303

304

305

306

307

308

309

310

311

312

313
Alston, J. M., R. J. Sexton, and M. Zhang. 1997. "The Effects of Imperfect Competition on the Size and Distribution of Research Benefits." American Journal of Agricultural Economics 79(4):1252-65.

Bergek, A., S. Jacobsson, B. Carlsson, S. Lindmark, and A. Rickne. 2008. "Analyzing the Functional Dynamics of Technological Innovation Systems: A Scheme of Analysis." Research Policy 37(3):407-29.

Bijman, J. and M. Hanisch. 2012. Support for Farmers Cooperatives: Developing a Typology of Cooperatives and Producer Organisations in the EU. Wageningen. Wageningen UR.

Brooks, S. and M. Loevinsohn. 2011. "Shaping Agricultural Innovation Systems Responsive to Food Insecurity and Climate Change." Natural Resources Forum 35(3):185-200.

Camanzi, L., G. Malorgio, and T. G. Azcárate. 2011. "The Role of Producer Organizations in Supply Concentration and Marketing: A Comparison between European Countries in the Fruit and Vegetable Sector." Journal of Food Products Marketing 17(2-3):327-54.

Dougherty, D. 2004. "Organizing Practices in Services: Capturing Practice-Based Knowledge for Innovation." Strategic Organization 2(1):35-64.

van den Driessen Mareeuw, F., L. Vaandrager, L. Klerkx, J. Naaldenberg, and M. Koelen. 2015. "Beyond Bridging the Know-Do Gap: A Qualitative Study of Systemic Interaction to Foster Knowledge Exchange in the Public Health Sector in The Netherlands." BMC Public Health 15(1):922.

Eide, P. J. 2008. "Recruiting Participants." Pp. 744-46 in The Sage Encyclopedia of Qualitative Research Methods, edited by L. M. Given. Thousand Oaks: SAGE Publications, Inc.

Esbjerg, L., S. Burt, H. Pearse, and V. Glanz-Chanos. 2016. "Retailers and TechnologyDriven Innovation in the Food Sector: Caretakers of Consumer Interests or Barriers to Innovation?" British Food Journal 118(6):1370-83.

Hall, A. 2007. "The Origins and Implications of Using Innovation Systems Perspectives in the Design and Implementation of Agricultural Research Projects: Some Personal Observations." UNU-MERIT Working Papers.

Hall, A., L. Mytelka, and B. Oyeyinka. 2006. "Concepts and Guidelines for Diagnostic Assessments of Agricultural Innovation Capacity." UNU-MERIT Working Papers $1-33$.

Hekkert, M. P., R. A. A. Suurs, S. O. Negro, S. Kuhlmann, and R. E. H. M. Smits. 2007. "Functions of Innovation Systems: A New Approach for Analysing Technological Change." Technological Forecasting \& Social Change 74(4):413-32.

Hermans, F., L. Klerkx, and D. Roep. 2015. "Structural Conditions for Collaboration and 
314

315

316

317

318

319

320

321

322

323

324

325

326

327

328

329

330

331

332

333

334

335

336

337

338

339

340

341

342

343

344

345

346

347

348

349

350

351

352

353

Learning in Innovation Networks: Using an Innovation System Performance Lens to Analyse Agricultural Knowledge Systems." The Journal of Agricultural Education and Extension 21(1):35-54.

Hermans, F., M. Stuiver, P. J. Beers, and K. Kok. 2013. "The Distribution of Roles and Functions for Upscaling and Outscaling Innovations in Agricultural Innovation Systems." Agricultural Systems 115:117-28.

Herstad, S. J., H. W. Aslesen, and B. Ebersberger. 2014. "On Industrial Knowledge Bases, Commercial Opportunities and Global Innovation Network Linkages." Research Policy 43(3):495-504.

Hingley, M. K. 2005. "Power Imbalanced Relationships: Cases from UK Fresh Food Supply." International Journal of Retail \& Distribution Management 33(8):551-69.

Hingley, M. K., A. Lindgreen, and B. Casswell. 2005. "Supplier-Retailer Relationships in the UK Fresh Produce Sector." Journal of International Food \& Agribusiness Marketing 18(1/2):49-86.

Hogeland, J. A. 2015. "Managing Uncertainty and Expectations: The Strategic Response of U.S. Agricultural Cooperatives to Agricultural Industrialization." Journal of CoOperative Organization and Management 3(2):60-71.

Hounkonnou, D., D. Kossou, T. W. Kuyper, C. Leeuwis, E. S. Nederlof, N. Röling, O. Sakyi-Dawson, M. Traoré, and A. van Huis. 2012. "An Innovation Systems Approach to Institutional Change: Smallholder Development in West Africa." Agricultural Systems 108:74-83.

Howells, J. 2006. "Intermediation and the Role of Intermediaries in Innovation." Research Policy 35(5):715-28.

Kebebe, E. 2018. "Bridging Technology Adoption Gaps in Livestock Sector in Ethiopia: A Innovation System Perspective." Technology in Society.

Kebebe, E., A. J. Duncan, L. Klerkx, I. J. M. de Boer, and S. J. Oosting. 2015. "Understanding Socio-Economic and Policy Constraints to Dairy Development in Ethiopia: A Coupled Functional-Structural Innovation Systems Analysis." Agricultural Systems 141(C):69-78.

Kilelu, C. W., L. Klerkx, and C. Leeuwis. 2014. "How Dynamics of Learning Are Linked to Innovation Support Services: Insights from a Smallholder Commercialization Project in Kenya." Journal of Agricultural Education and Extension 20(2):213-32.

Klein Woolthuis, R., M. Lankhuizen, and V. Gilsing. 2005. "A System Failure Framework for Innovation Policy Design." Technovation 25:609-19.

Klerkx, L., N. Aarts, and C. Leeuwis. 2010. "Adaptive Management in Agricultural Innovation Systems: The Interactions between Innovation Networks and Their Environment." Agricultural Systems 103(6):390-400.

Klerkx, L., S. Adjei-Nsiah, R. Adu-Acheampong, A. Sal"lidou, E. Zannou, L. Soumano, O. Sakyi-Dawson, A. van Paassen, S. Nederlof, A. Saïdou, E. Zannou, L. Soumano, O. Sakyi-Dawson, A. van Paassen, and S. Nederlof. 2013. "Looking at 
369

370

371

372

373

374

375

376

377

378

379

380

381

382

383

384

385

386

387

388

389

390

391

392

Agricultural Innovation Platforms through an Innovation Champion Lens." Outlook on Agriculture 42(3):185-92.

Klerkx, L., K. de Grip, and C. Leeuwis. 2006. "Hands off but Strings Attached: The Contradictions of Policy-Induced Demand-Driven Agricultural Extension." Agriculture and Human Values 23(2):189-204.

Klerkx, L. and C. Leeuwis. 2008a. "Balancing Multiple Interests: Embedding Innovation Intermediation in the Agricultural Knowledge Infrastructure." Technovation 28(6):364-78.

Klerkx, L. and C. Leeuwis. 2008b. "Matching Demand and Supply in the Agricultural Knowledge Infrastructure: Experiences with Innovation Intermediaries." Food Policy 33(3):260-76.

Klerkx, L. and C. Leeuwis. 2009. "Establishment and Embedding of Innovation Brokers at Different Innovation System Levels: Insights from the Dutch Agricultural Sector." Technological Forecasting and Social Change 76(6):849-60.

Klerkx, L., B. van Mierlo, and C. Leeuwis. 2012. "Evolution of Systems Approaches to Agricultural Innovation: Concepts, Analysis and Interventions." Pp. 457-83 in Farming Systems Research into the 21st Century: The New Dynamic, edited by I. Darnhofer, D. Gibbon, and B. Dedieu. Dordrecht: Springer Netherlands.

Klerkx, L. and A. Proctor. 2013. "Beyond Fragmentation and Disconnect: Networks for Knowledge Exchange in the English Land Management Advisory System." Land Use Policy 30(1):13-24.

Klerkx, L., M. Schut, C. Leeuwis, and C. Kilelu. 2012. "Advances in Knowledge Brokering in the Agricultural Sector: Towards Innovation System Facilitation." IDS Bulletin 43(5):53-60.

Lamprinopoulou, C., A. Renwick, L. Klerkx, F. Hermans, M. Islam, and D. Roep. 2012. "A Systemic Policy Framework: The Cases of Scottish and Dutch Agrifood Innovation Systems." in 131st EAAE Seminar "Innovation for Agricultural Competitiveness and Sustainability of Rural Areas." Prague.

Leeuwis, C. 2000. "Learning to Be Sustainable. Does the Dutch Agrarian Knowledge Market Fail?" The Journal of Agricultural Education and Extension 7(2):79-92.

Leeuwis, C. 2004. Communication for Rural Innovation: Rethinking Agricultural Extension. 3rd ed. Wiley-Blackwell.

Legge, A., J. Orchard, A. Greenhalgh, and P. and K. Ulrich. 2006. The Production of Fresh Produce in Africa for Export to the United Kingdom: Mapping Different Value Chains. Chatham.

Mason, J. 1996. Qualitative Researching. 2nd ed. SAGE Publications.

Menary, J. 2015. "Agricultural Innovation: Lessons from Medicine." InImpact The Journal of Innovation Impact 8(1):93-115.

Menary, J. 2018. "Innovation in the UK Fresh Produce Industry: Sources, Barriers and 
393

394

395

396

397

398

399

400

401

402

403

404

405

406

407

408

409

410

411

412

413

414

415

416

417

418

419

420

421

422

423

424

425

426

427

428

429

430
Innovative Capacity." University of Warwick.

Metcalfe, S. 2007. "Innovation Systems, Innovation Policy and Restless Capitalism." in Perspectives on Innovation, edited by F. Malerba and S. Brusoni. Cambridge University Press.

Meulen, B. van der, M. Nedeva, and D. Braun. 2005. "Intermediaries Organisation and Processes: Theory and Research Issues." in PRIME Workshop.

Meulen, B. van der, J. de Wilt, and H. Rutten. 2003. "Developing Futures for Agriculture in the Netherlands: A Systematic Exploration of the Strategic Value of Foresight." Journal of Forecasting 22(2-3):219-33.

Mylan, J., F. W. Geels, S. Gee, and A. McMeekin. 2015. "Eco-Innovation and Retailers in Milk, Beef and Bread Chains: Enriching Environmental Supply Chain Management with Insights from Innovation Studies." Journal of Cleaner Production 107:20-30.

National Horticultural Forum. 2011. A New Vision for Horticulture R\&D.

Office for National Statistics. 2018. Labour in the Agriculture Industry, UK: February 2018.

Palys, T. 2008. "Purposive Sampling." Pp. 697-98 in The Sage Encyclopedia of Qualitative Research Methods. Vol. 2. SAGE.

Pascucci, S., C. Gardebroek, and L. Dries. 2012. "Some like to Join, Others to Deliver: An Econometric Analysis of Farmers' Relationships with Agricultural CoOperatives." European Review of Agricultural Economics 39(1):51-74.

Pollock, C. 2012. "Repairing a Fractured Pipeline: Improving the Effectiveness of Agricultural R\&D in the UK." International Journal of Agricultural Management 2(1):1-4.

Prager, K., P. Labarthe, M. Caggiano, and A. Lorenzo-Arribas. 2016. "How Does Commercialisation Impact on the Provision of Farm Advisory Services? Evidence from Belgium, Italy, Ireland and the UK." Land Use Policy 52:329-44.

Retail Think Tank, KPMG, and Ipsos Retail Performance. 2014. The Future of the Grocery Sector in the UK.

Revoredo-Giha, C., P. M. K. Leat, A. W. Renwick, and C. Lamprinopoulou-Kranis. 2012. "Innovation and Power in Food Supply Chains: The Case of the Potato Sector in the UK." in Working Papers 142544. Scotland's Rural College (formerly Scottish Agricultural College), Land Economy \& Environment Research Group.

Ritchie, J. and J. Lewis. 2010. Qualitative Research Practice. 3rd ed. SAGE Publications Ltd.

Röling, N. 2009. "Pathways for Impact: Scientists' Different Perspectives on Agricultural Innovation." International Journal of Agricultural Sustainability 7(2):83-94.

Ryan, G. W. and H. R. Bernard. 2003. "Techniques to Identify Themes." Field Methods 
431

432

433

434

435

436

437

438

439

440

441

442

443

444

445

446

447

448

449

450

451

452

453

454

455

456

457

458

459

460

461

462

463

464

465

466

467

468

469

15(1):85-109.

Schut, M., A. van Paassen, C. Leeuwis, and L. Klerkx. 2014. "Towards Dynamic Research Configurations: A Framework for Reflection on the Contribution of Research to Policy and Innovation Processes." Science and Public Policy 41(2):207-18.

Schut, M., J. Rodenburg, L. Klerkx, J. Kayeke, A. van Ast, and L. Bastiaans. 2015. "RAAIS: Rapid Appraisal of Agricultural Innovation Systems (Part II). Integrated Analysis of Parasitic Weed Problems in Rice in Tanzania." Agricultural Systems 132:12-24.

Smedlund, A. 2006. "The Roles of Intermediaries in a Regional Knowledge System." Journal of Intellectual Capital 7(2):204-20.

Smits, R. and S. Kuhlmann. 2004. "The Rise of Systemic Instruments in Innovation Policy." International Journal of Foresight and Innovation Policy 1(1/2):4.

Sodano, V. and M. Hingley. 2009. "Channel Management and Differentiation Strategies in the Supply Chain for Fresh Produce." Journal of Food Products Marketing 16(1):129-46.

Spielman, D. J., J. Ekboir, and K. Davis. 2009. "The Art and Science of Innovation Systems Inquiry: Applications to Sub-Saharan African Agriculture." Technology in Society 31(4):399-405.

Srivastava, A. and S. B. Thomson. 2009. "Framework Analysis: A Qualitative Methodology for Applied Policy Research." Journal of Administration \& Governance 4(2):72-79.

Struik, P. C., L. Klerkx, and D. Hounkonnou. 2014. "Unravelling Institutional Determinants Affecting Change in Agriculture in West Africa." International Journal of Agricultural Sustainability 12(3):370-82.

Sutherland, L.-A., J. Mills, J. Ingram, R. J. F. Burton, J. Dwyer, and K. Blackstock. 2013. "Considering the Source: Commercialisation and Trust in Agri-Environmental Information and Advisory Services in England." Journal of Environmental Management 118(C):96-105.

The World Bank. 2006. Enhancing Agricultural Innovation: How to Go Beyond the Strengthening of Research Systems. Washington, D. C.

Turner, J. A., L. Klerkx, K. Rijswijk, T. Williams, and T. Barnard. 2016. "Systemic Problems Affecting Co-Innovation in the New Zealand Agricultural Innovation System: Identification of Blocking Mechanisms and Underlying Institutional Logics." NJAS - Wageningen Journal of Life Sciences 76:99-112.

UK Government. 2013a. A UK Strategy for Agricultural Technologies. London.

UK Government. 2013b. Crops and Horticulture Policy Delivery Evidence Plan.

UK Government. 2014a. Animal and Plant Health in the UK: Building Our Science Capability. 
470 UK Government. 2014b. Protecting Plant Health: A Biosecurity Strategy for Great $471 \quad$ Britain.

472 UK Government. 2018. Horticulture Statistics 2017.

473 Villaverde, J. J., B. Sevilla-Morán, P. Sandín-España, C. López-Goti, and J. L. Alonso-

474

475 Prados. 2014. "Biopesticides in the Framework of the European Pesticide Regulation (EC) No. 1107/2009." Pest Management Science 70(1):2-5.

476

477

478

Wamae, W., P. Goyal-Rutsaert, M. Morgan Jones, S. Ni Chonaill, J. Tait, and J. Chataway. 2011. Translational Research and Knowledge in Agriculture and Food Production. RAND Corporation.

479

480

481

482

Weber, K. M. and H. Rohracher. 2012. "Legitimizing Research, Technology and Innovation Policies for Transformative Change: Combining Insights from Innovation Systems and Multi-Level Perspective in a Comprehensive 'Failures' Framework." Research Policy 41(6):1037-47.

483

484

485

Wieczorek, A. J. and M. P. Hekkert. 2012. "Systemic Instruments for Systemic Innovation Problems: A Framework for Policy Makers and Innovation Scholars." Science and Public Policy 39(1):74-87.

486 Young, L. M. and J. E. Hobbs. 2002. "Vertical Linkages in Agri-Food Supply Chains: Changing Roles for Producers, Commodity Groups, and Government Policy." Review of Agricultural Economics 24(2):428-41. 